\title{
REFLEXÕES SOBRE OS PRINCIPAIS DESAFIOS DA EDUCAÇÃO AMBIENTAL: UMA PERSPECTIVA INTERDISCIPLINAR
}

\author{
REFLECTIONS ON THE MAIN CHALLENGES OF ENVIRONMENTAL EDUCATION: AN INTERDISCIPLINARY PERSPECTIVE
}

\author{
DE JESUS, Samuel José Amaral 1
}

1Programa de Pós-Graduação em Modelagem em Ciências da Terra e do Ambiente, Universidade Estadual de Feira de Santana. Feira de Santana, Bahia, Brasil.

\begin{abstract}
RESUMO
Os estudos em Educação Ambiental possibilitam, ao indivíduo e comunidades, a construção de atitudes, valores, competência e habilidades de suma importância à qualidade de vida, bem como para o desenvolvimento sustentável e à transformação humana. Mesmo com um arcabouço legal que normatiza e protege o meio ambiente, os recursos naturais continuam a sofrer as consequências das ações antrópicas, um fato que necessita ser remediado pela educação, que é a principal estratégia para a mudança de atitudes. A universidade adentra a discussão justamente por conciliar o ensino, a pesquisa e extensão, em espaços que propiciam esse desenvolvimento. Sendo assim, o presente artigo tem como proposta avaliar os modos de inserção e as perspectivas de Educação Ambiental, na formação e na prática docente de pós-graduandos em Ciências Ambientais, por ser um programa multidisciplinar, que permite trabalhar com amplos saberes, a partir do envolvimento de graduados das diversas áreas do conhecimento. O estudo se deu através de uma pesquisa bibliográfica, de caráter descritivo e com abordagem quali-quantitativa, que contou com a participação de 10 estudantes de pós-graduação de uma universidade do Nordeste. Os participantes tinham idades entre 18 e 34 anos, sendo 50\% formados em Geografia, os demais em História, Biologia, Engenharia e Saúde. Cerca de 70\% trabalharam com Educação Ambiental na sala de aula, 40\% afirmaram que o tema ainda é pouco abordado, sendo que $80 \%$ alegaram estar prontos para atuar como educadores nessa perspectiva. O desmatamento, queimadas, acúmulo de lixo, desperdício de água e relacionados, foram destacados como assuntos para discussão. Conclui-se que a visão sustentável é fundamental às boas atitudes, sem prejuízo às futuras gerações, e que os conceitos de Educação Ambiental estão na formação, devendo ser colocados em prática nas ações cotidianas.
\end{abstract}

Palavras-chave: Meio Ambiente. Pesquisa Interdisciplinar. Educação Superior.

\begin{abstract}
Studies in Environmental Education make it possible for individuals and communities to build attitudes, values, competence and skills that are important for quality of life, sustainable development and human transformation. Even though there is a legal framework that regulates and protects the environment, the natural resources continue to suffer the consequences of anthropic actions. This fact needs to be remedied by education, as this is the main strategy for changing attitudes. The university enters the discussion because it conciliates the teaching, the research and the extension, in spaces that allow this development. This article aims to evaluate the modes of insertion and the perspectives of Environmental Education in the formation and teaching practice of graduate students in Environmental Sciences. This is a multidisciplinary program that allows working with broad knowledge, based on the involvement of graduates from various areas of knowledge. The study was conducted through a descriptive bibliographic research with a qualitative and quantitative approach, which was attended by 10 postgraduate students from a university in the Northeast. The participants were between 18 and 34 years old, 50\% graduated in Geography, others in History, Biology, Engineering and Health. About 70\% worked with Environmental Education in the classroom, 40\% said that the subject is still little addressed, and $80 \%$ claimed to be ready to act as educators in this perspective. The deforestation, the burning, the garbage accumulation, the waste water and related were highlighted as topics for discussion. It is concluded that sustainable vision is fundamental to good attitudes, without prejudice to future generations, and that the concepts of Environmental Education are in the formation, and should be put into practice in daily actions.
\end{abstract}

Keywords: Environment. Interdisciplinary Placement. University Education. 


\section{INTRODUÇÃO}

A percepção ambiental diz respeito ao modo como um sujeito ou grupo contempla e estabelece conexões com o ambiente que o cerca e com os demais indivíduos em seu entorno. Nesse cenário, a Educação Ambiental funciona como veículo que permite refletir sobre a prática da sociedade num contexto permeado pela degradação. Esse modelo de educação pode ser definido como um instrumento formativo e promotor da cidadania, com estímulo à consciência crítica, sobre os aspectos que envolvem o meio ambiente. Assim, ele abre espaço para que tanto o indivíduo quanto as coletividades possam construir valores, atitudes, habilidades e competências voltadas especialmente para a conservação, para a qualidade de vida e à sustentabilidade, observando-se o que é de uso comum da população, que deve estar presente em todas as formas do processo educativo, tanto no âmbito formal quanto no informal ${ }^{1,2}$.

Esse processo não se dá em um único momento. Sob caráter permanente, envolve a participação da coletividade na troca e disseminação de conhecimentos, bem como normas, capacidades, experiências, projetos e outros meios, pensando-se nos problemas atuais e nos prováveis entraves futuros. Demanda uma postura dialógica, que questione a realidade e os comportamentos humanos, numa conexão com a saúde coletiva, a gestão dos recursos e as diferentes forças sociais para a tomada de decisões, com eficiência, praticidade, autonomia, sem qualquer forma de discriminação ou dominação social, a favor de uma sociedade que seja cada vez mais sustentável. Essas questões conduzem a estratégias e soluções com princípios sólidos, em que a comunidade e os empreendimentos diversos podem colaborar para uma mudança tanto individual quanto coletiva ${ }^{2,3}$.

De acordo com uma das publicações do Programa Nacional de Educação Ambiental e Mobilização Social em Saneamento (PEAMSS) ${ }^{3}$, há uma série de questionamentos que precisam ser levados em conta, por exemplo:

Todas essas ações têm a sua contribuição e a sua importância, mas será que dessa forma conseguiremos efetivamente atingir os objetivos de fundo que nos movem? Se todos deixassem de jogar lixo no chão, se todo o nosso lixo fosse separado e reciclado e se todas as crianças aprendessem sobre meio ambiente $e$ saneamento teríamos um mundo mais justo e um ambiente mais saudável? Saber mais sobre meio ambiente e o que é o saneamento é o suficiente para uma mudança de ação e reflexão do indivíduo e do coletivo? Será que cabe às crianças reverter esse quadro ou é uma responsabilidade de todos e necessidade da mudança do modelo econômico e de desenvolvimento em que vivemos? (p. 13).

Percebe-se que há uma estreita relação entre o homem e o meio ambiente, em que a percepção (mais uma vez) se torna fundamental para que essa interação ocorra de forma saudável, pois o País encontra-se diante de diversos problemas ambientais que demandam uma rápida resolução. Isso porque, apesar dos arcabouços legislativos vigentes, como a Política Nacional do Meio
Ambiente (Lei ํo. 6.938/1981), a Constituição Federal (1988), a Política Nacional de Educação Ambiental (PNEA - Lei no. 9.795/1999), o PEAMSS (2009), o meio natural vem sofrendo sérios impactos decorrentes da ação antrópica em usar os recursos naturais disponíveis de forma incorreta. Este fato tem desencadeado as diversas formas de desgaste do meio ambiente, como a poluição (da água, do solo, do ar), o desmatamento, a redução de vida aquática, a morte de diversas espécies da flora e da fauna, a deposição incorreta dos resíduos sólidos e outros aspectos, como um reflexo direto do consumismo e da mera satisfação do homem com o tempo presente ${ }^{4,5}$.

A universidade adentra este diálogo por se tratar de um local voltado diretamente à discussão, construção e reflexão sobre a realidade socioambiental, independente de qual seja o nível ou o curso de formação. Isso ocorre porque o ensino, a pesquisa e a extensão permitem formar o indivíduo como um cidadão-profissional, que não apenas desempenha as tarefas que são inerentes à sua graduação ou pós-graduação, mas é capaz de agir em prol da transformação do meio no qual se encontra inserido, com responsabilidade. Acredita-se que seja algo que começa na escola e se perpetua pelas universidades. No entanto, quando o sujeito está no nível superior, encontra-se diante de um espaço para o desenvolvimento direto da Educação Ambiental, visto que o "meio ambiente" é abordado de forma mútua entre ensino, pesquisa e extensão, permitindo a aplicação das normas do PNEA na meta de transformar o homem, a favor do desenvolvimento sustentável, que se reflete nas atitudes dos indivíduos e da coletividade ${ }^{6}$.

Desse modo, a Educação Ambiental faz-se necessária para que haja superação dos impasses observados neste nível, como também a construção de uma sociedade que seja menos consumista e, ao mesmo tempo, mais sustentável e racional. Isso envolve a análise de diversos fatores: socioeconômicos, culturais, históricos e geográficos da humanidade, incluindo a saúde e a qualidade de vida. Diante dos aspectos outrora elencados, a presente produção tem como objetivo avaliar a inserção e as perspectivas de Educação Ambiental na formação e na prática docente de pós-graduandos em Ciências Ambientais.

\section{MÉTODOS}

Este trabalho condiz com uma pesquisa transversal e descritiva, com abordagem quali-quantitativa. $O$ estudo foi considerado transversal por ter sido realizado em um curto tempo, o que permitiu uma rápida condução da pesquisa, bem como a sua finalização, visto que a avaliação de cada participante ocorreu em um único momento. O seu caráter descritivo se deve ao fato de que permite observar a frequência, a distribuição das variáveis, suas características, causalidades e relações, bem como registrar os fatos observados pelo pesquisador, através da utilização de técnicas padronizadas ${ }^{7,8}$.

Foi utilizado como estratégia / instrumento, para a coleta de dados, um questionário online, de caráter misto (com perguntas abertas e fechadas) com 15 questões. Os 
participantes foram estudantes de mestrado acadêmico, vinculados a um Programa de Pós-Graduação da área de Ciências Ambientais, de uma universidade do Nordeste brasileiro. A escolha desses participantes se deu pelo fato de se tratar de um programa com caráter multidisciplinar, que envolve profissionais de diversos campos de atuação. Desse modo, foi selecionada uma turma, sendo os membros convidados aleatoriamente para o estudo.

Para a aplicação do questionário, foi utilizado um portal de registro gratuito chamado "Online Pesquisa"9, que possui uma interface de fácil aplicação e muito autoexplicativa, que possibilita ao usuário a construção de questionários de rápido alcance, em poucos minutos, de forma personalizada e sem limite de tempo, conforme o usuário desejar. Envolveu, por exemplo, questões de "sim" ou "não", perguntas abertas e fechadas (única opção, múltipla escolha). Diante disso, não foi necessário o uso de outros softwares, pois essa ferramenta já fornece todos os resultados, e permitiu assim a geração dos dados da pesquisa através do Microsoft Office Excel (no formato .xlsx), para o sistema Windows, numa versão adaptável, visto que as respostas dos participantes também são apresentadas na página exclusiva do usuário, em tempo real, com relatórios gerados automaticamente na forma de gráficos e planilhas, além de possibilitar a tabulação cruzada e a filtração de dados.

As questões recebidas pelos participantes foram as seguintes:

1. Sexo (Masculino / Feminino);

2. Idade (18-24 / 25-29 / 30-34 / 35-39 / 40 anos ou mais);

3. Graduação;

4. Você já atuou ou atua como docente? (Sim / Não);

5. A sua graduação contribuiu, de alguma forma, à reflexão sobre os aspectos ambientais, com ênfase na sustentabilidade? (Sim / Não);

6. Você já fez algum curso que lhe permitiu refletir ou mudar de postura quanto à educação ambiental? (Sim / Não);

7. Já trabalhou com esta temática na sala de aula? (Sim / Não);

8. Através de quais instrumentos você obtém informações sobre o meio ambiente? (Eventos científicos / TV / Jornais, revistas / Internet / Livros / Observação da paisagem / Outros:

9. Você considera fundamental que, no meio escolar ou acadêmico, sejam realizadas atividades sobre a conservação da natureza? (Sim / Não);

10. O seu interesse em estudar / refletir sobre questões socioambientais (Muito / Pouco / Razoável / Nenhum / Não sei responder);

11. O nível em que esses temas são abordados na educação em geral (Alto / Moderado / Baixo / Muito baixo / Não sei);

12. Que ações você realiza em prol da conservação? (Planto árvores / Não desperdiço água / Divulgo as causas ecológicas / Economizo energia elétrica / Separo o lixo para a reciclagem / Uso produtos ecológicos / Outras:
13. Quais recursos ou atividades podem ser empregados para trabalhar a educação ambiental na escola ou universidade? (Materiais audiovisuais / Um blog para divulgação do tema / Grupo de pesquisa interdisciplinar / Painel temático, apresentação teatral, etc. / Eventos com pessoas que atuem nessa perspectiva / Visitas técnicas a instituições relacionadas / Outros: );

14. Quais os principais problemas que precisam ser fortemente discutidos na comunidade acadêmica, em relação à sustentabilidade? (O desperdício de água e de energia / O acúmulo de lixo nas ruas / A poluição em geral / O desmatamento / As queimadas / Não sei / Outros: );

15. Você se sente pronto(a) para atuar como educador(a) ambiental? Justifique.

Sendo assim, os estudantes receberam um link de acesso por email, através do qual foram convidados para participar do estudo. Todos pertenciam à mesma turma, numa média de 14 alunos, advindos de diferentes formações. Durante o convite foram informados sobre a data limite para o envio das respostas através do formulário online. Após este período, o pesquisador buscou os resultados na ferramenta "Online Pesquisa" e a partir daí deu início às inferências sobre o tema, por meio de uma análise descritiva, com confronto dos dados, por meio dos achados da literatura.

\section{RESULTADOS E DISCUSSÃO}

Entre os 14 pós-graduandos convidados para participar do estudo, somente 10 responderam o questionário de acordo com o prazo estabelecido, visto que o portal online encerra o link de acesso após decorrido o tempo estabelecido pelo usuário, para a resposta dos participantes.

Quanto ao perfil, os indivíduos que participaram tinham idades entre 18 e 34 anos, com predominância na faixa etária entre 18 e 29 anos. Cerca de $60 \%$ pertenciam ao sexo feminino. Quanto à formação acadêmica, no que diz respeito ao curso de graduação, 50\% eram formados em Licenciatura em Geografia (sendo que uma também possui Bacharelado na área), enquanto os demais se graduaram em outros campos do conhecimento, como: Licenciatura em História, em Ciências Biológicas; Bacharelado em Enfermagem, em Biomedicina, Engenharia Florestal. No que diz respeito à experiência enquanto professores (seja na educação básica ou no ensino superior), grande parte já atuou como docente (80\%). Os demais iniciaram o mestrado também com a expectativa de exercer a docência.

Em relação às perguntas voltadas para a Educação Ambiental, todos salientaram que a graduação contribuiu quanto à reflexão sobre aspectos ambientais, com ênfase na sustentabilidade, sendo que apenas $70 \%$ já trabalharam com essa temática na sala de aula e apenas um indivíduo nunca participou de cursos voltados à educação ambiental. 
Sobre os instrumentos que os participantes utilizam para obter informações sobre o meio ambiente, prevaleceram: participação em eventos científicos, jornais e revistas, uso da internet, livros, e, inclusive, a observação da paisagem. Quanto às ações desempenhadas em prol da conservação, vale destacar: a divulgação de causas ecológicas, a economia de energia elétrica e de água no cotidiano, a colaboração no plantio de árvores, a separação do lixo para a reciclagem.

Retomando as questões sobre os aspectos da sala de aula, $40 \%$ dos participantes declararam que o tema "educação ambiental" ainda tem sido pouco abordado, e outros $40 \%$ que ocorre moderadamente. Entre os recursos e atividades que os mesmos consideram que podem ser empregados para mudar esse cenário, destacaram os eventos com profissionais da área $(100 \%)$, painéis temáticos e apresentações teatrais $(90 \%)$, os grupos de pesquisa interdisciplinar (80\%), uso de materiais audiovisuais $(90 \%)$, as visitas técnicas a instituições envolvidas nessa causa (90\%). Sobre os temas para discussão na comunidade acadêmica, os participantes destacaram: desmatamento (100\%), acúmulo de lixo e/ou desperdício de água e energia (90\%), queimadas $(70 \%)$ e ainda acrescentaram outros, tais como: animais nas ruas, consumismo, contexto socioeconômico das famílias, e políticas públicas.

Ao final, eles foram questionados se estão prontos para atuar como educadores ambientais - $80 \%$ acreditaram que sim, especialmente por conta da formação da graduação e/ou do mestrado, e do conhecimento que já possuem sobre a temática, pois desde então todos já são professores, ainda que não tenham exercido diretamente a docência. Entre as justificativas que foram apresentadas nessa questão, valem ser destacadas:

"Ao longo da minha formação pedagógica tive a oportunidade de construir, desconstruir e refletir sobre diversos temas ambientais. Entender a importância dos recursos naturais $e$ interferências/transformações antrópicas do espaço geográfico" (Participante 02).

"Conheço algumas causas e consequências dos problemas ambientais e alternativas para amenizá-los. Porém, como toda educadora, estudiosa e pesquisadora, necessito estar me atualizando em relação a esta temática, repensando antigas práticas e descobrindo novos caminhos na busca da sustentabilidade ambiental" (Participante 06).

"A educação ambiental é acrescentar, sensibilizar o público em geral sobre a importância da questão ambiental, que está intrinsecamente ligada à realidade do nosso dia a dia, é uma questão ou tema interdisciplinar que envolve questões não somente ao nosso entorno, mas temas globais. É necessário contextualizar, explicar os fatos $e$ consequências sobre conservação, sustentabilidade como foco na realidade socioeconômica. Aquele que pratica a educação ambiental no âmbito de ensino é conhecido como "educador ambiental" e não precisa, necessariamente, ser um professor. Pois trata-se, como foi citado, de uma área interdisciplinar que envolve toda a comunidade da sociedade. Quem está voltado à área possui ações e atitudes ou competências voltadas para a conservação do meio ambiente, pode de alguma forma multiplicar conhecimentos e ações essenciais à qualidade de vida e sustentabilidade" (Participante 07).

"Em mim existe essa consciência e a necessidade de conscientizar outras pessoas, levando em consideração a minha formação acadêmica, intelectual e contexto social. Me sinto apta a trabalhar como educador na área, e ressaltando ainda a minha vontade de aprender cada vez mais no âmbito da educação ambiental" (Participante 09).

Grande parte das perguntas tinha uma opção, sendo que as questões relacionadas às ações, recursos e problemas ambientais foram de múltipla escolha, já que os sujeitos participantes poderiam estar envolvidos em diversas atividades, bem como apresentar uma série de aspectos que necessitam de discussão, pois o tema "sustentabilidade" é muito amplo e leva os pesquisadores à investigação e questionamentos para si mesmos e para outros indivíduos, no que diz respeito às mais diversas situações com enfoque na Educação Ambiental, para este contexto. Somente a última pergunta concedeu uma abertura maior, para que os participantes refletissem mais sobre a sua formação, olhando "para dentro de si", a fim de descobrirem e opinarem se realmente estão prontos para atuarem na qualidade de educadores ambientais, ainda que não seja diretamente em uma sala de aula.

Alencar e Barbosa ${ }^{6}$ afirmam que "o Brasil pode ser visto como um dos países com um maior conjunto normativo de proteção ambiental, no entanto, na maioria dos casos, o problema esbarra na falta de suporte e de conhecimento necessário sobre tais questões" (p. 232). Isso leva a refletir que, de fato, a educação é a chave para as mudanças ambientais, e que temas como o deste estudo são fundamentais para a formação acadêmica, bem como para o incentivo à adoção de estratégias de sustentabilidade na sala de aula, no ambiente de trabalho, enfim, no contexto em que os formadores de opinião estão inseridos, não na perspectiva de apontar, mas de incentivar uma nova visão de mundo, que traga esperança e a possibilidade de reconstrução da natureza, a partir da preservação dos recursos que ainda se encontram disponíveis, para esta e as futuras gerações.

Os temas destacados para discussão, pelos participantes, refletem 0 quanto 0 ser humano se corrompeu diante dos processos da globalização, o que o levou a conviver e a viver de forma inconsequente e irresponsável, pois grande parte dos desastres que hoje são contemplados são frutos das ações antrópicas. Os recursos têm sido explorados de forma demasiada, sem uma visão consciente, que tem conduzido à escassez como também para a extinção das diversas formas de vida. Por outro lado, há muitos que estão insensíveis, por 
não terem presenciado, "sentido na pele" uma situação de desastre ou desgaste ambiental, mesmo os noticiários alertando e apresentando cotidianamente como o país se encontra: em meio a uma crise socioambiental que pode ser revertida. Não obstante, a educação no ensino superior ainda precisa de reflexões sólidas em suas propostas curriculares que, de alguma forma, gerem mudanças racionais, práticas pedagógicas e didáticas, e compreensão profunda da problemática ambiental, capazes de sistematizar, divulgar e propor experiências em sustentabilidade ${ }^{10,11}$.

Zupelari e Wick ${ }^{12}$ refletem que a humanidade se encontra diante de uma incerteza em relação ao futuro, pois há um desconforto sendo gerado pela degradação dos recursos, aliado às pressões do capitalismo, ao desbalanço das relações sociais, estas que estão repletas de angústia e insegurança. Os participantes enfatizaram a importância do lúdico, bem como de ações educacionais em saúde que possam reverter esse quadro, por meio de estratégias que despertem a atenção para uma realidade e convoquem o povo para uma mudança que já se encontra em estado de urgência. Estratégias educacionais, na visão de Jesus ${ }^{13}$, intercalam saberes e recursos que podem alcançar as famílias e comunidades, de modo a ultrapassar a dimensão biológica, para então abrir espaço para uma discussão que envolve a qualidade e as dimensões cotidianas, alicerçando o conhecimento científico ao popular, em adaptação para cada contexto, a favor do cumprimento do direito à saúde e qualidade de vida proposto constitucionalmente.

Essas atividades podem ser realizadas não somente nas universidades, mas nas escolas, que são como uma porta de entrada para a inserção das competências, atitudes, valores e habilidades essenciais para a promoção da qualidade de vida e manutenção do meio ambiente. A música, o teatro, as palestras com profissionais inseridos no contexto, as visitas às instituições competentes, são algumas das atividades que os pesquisadores, os acadêmicos e profissionais podem desenvolver para todos os níveis de ensino, com ênfase na Educação Básica, a partir de ações concretas. Sendo que a sensibilidade individual é tarefa da escola e de toda a sociedade, devendo todos os cidadãos estar cientes dos seus direitos e deveres quanto ao meio ambiente, e das inter-relações existentes, o que demanda a adoção de um programa eficiente em prol da preservação dos recursos naturais ${ }^{14,15}$.

Por outro lado, a preocupação com a sustentabilidade ambiental já é uma evidência para a sociedade, apesar de que há um longo caminho a ser percorrido. Os municípios têm criado leis que regulamentam, por exemplo, a coleta seletiva, mas cabe a cada cidadão $o$ respeito e cumprimento dessas exigências, o que também é um dever das empresas diante da sociedade. Os sujeitos do estudo demonstraram essa preocupação e têm agido por meio de diversas atividades, com destaque à divulgação de causas ecológicas. Alguns realizam atividades práticoecológicas, como plantio de árvores, separação do lixo para reciclagem e, cotidianamente, eles economizam água e energia elétrica, em sua maioria, o que pode ser considerado como um grande diferencial. Vale lembrar que o "meio ambiente" encontra-se entre os temas transversais e interdisciplinares, no que diz respeito ao currículo escolar brasileiro (inserido nos Parâmetros Curriculares Nacionais), e deve ser promovido por meio do vínculo entre as disciplinas, integrando as áreas do conhecimento, alicerçando ciência, trabalho, arte e tecnologia, bem como repercutir sobre os diferentes setores sociais, como educação, saúde, alimentação, agricultura, transportes e outros ${ }^{15,16}$.

O questionário finaliza com a necessidade de se refletir sobre o que é ser, de fato, um educador ambiental, e se os pós-graduandos estão preparados para esta tarefa que não é nada fácil. Nesse aspecto, é preciso ter conhecimento sobre as tendências pedagógicas e, de algum modo, alicerçá-las à sua própria formação, ainda que o curso de graduação não tenha promovido essa relação, o que se observa amplamente nas formações para o bacharelado, que não possui ligação direta com a atuação para a docência. No entanto, é certo que a universidade funciona como centro investigativo, devendo os profissionais que são educadores ambientais compreender, refletir e analisar os processos aqui apresentados sob uma perspectiva ambiental, bem como as diversas políticas relacionadas, visto que a sua formação está direcionada para a sustentabilidade. Os cidadãos devem ser orientados, a partir dos espaços de educação, o que começa pela qualificação do educador, para então consolidar a sua prática e, portanto, ampliar a sua discussão sobre a natureza e sociedade, em comunhão com as diversas áreas do conhecimento ${ }^{17}$.

\section{CONSIDERAÇÕES FINAIS}

Ter uma visão voltada para a sustentabilidade permite ao cidadão agir no presente, conscientizando a si mesmo e à comunidade em que está inserido, satisfazendo-se pelo uso do que o ambiente dispõe, de forma a não prejudicar as futuras gerações. Os profissionais participantes apresentaram este perfil, esta preocupação, e deixaram claro que os conceitos da Educação Ambiental já fazem parte de sua formação, desde as primeiras construções no âmbito universitário, apesar de alguns ainda não se sentirem preparados para atuar nesta modalidade como educadores. Salientando que atuar na Educação Ambiental não demanda ser um licenciado nem ter uma formação voltada para a sala de aula, mas estar qualificado para abordar e trabalhar com as questões relacionadas ao meio ambiente, o que implica ensino, pesquisa e extensão em quaisquer níveis, mediante a sua dedicação. No entanto, torna-se clara a dimensão do problema, como também o interesse de diversas áreas de atuação em refletir sobre os aspectos apresentados neste texto, colaborar em suas próprias ações cotidianas e imprimir esses aspectos na atuação acadêmica.

\section{CONFLITOS DE INTERESSES}

Não existem conflitos de interesses no que diz respeito à submissão / publicação deste manuscrito em periódicos científicos. 


\section{REFERÊNCIAS}

1. Piccoli AS, Kligerman DC, Cohen SC, Assumpção RF. A Educação Ambiental como estratégia de mobilização social para o enfrentamento da escassez da água. Ciênc. Saúde Colet. 2016; 21(3):797-808.

2. Brasil. Presidência da República. Casa Civil. Subchefia para Assuntos Jurídicos. Lei no. 9.795, de 27 de abril de 1999. Dispõe sobre a educação ambiental, institui a Política Nacional de Educação Ambiental e dá outras providências. Brasília, DF; 1999.

3. Brasil. Ministério das Cidades. Secretaria Nacional de Saneamento Ambiental. Programa de Educação Ambiental e Mobilização Social em Saneamento. Caderno metodológico para ações de educação ambiental e mobilização social em saneamento. Brasília, DF; 2009.

4. Barboza LAS, Brasil DSB, Conceição GS. Percepção ambiental dos alunos do $6^{\circ}$ e do $9^{\circ}$ anos de uma escola pública municipal de Redenção, Estado do Pará, Brasil. Rev. Pan-Amaz Saúde. 2016; 7(4):11-20.

5. Gouveia N. Saúde e meio ambiente nas cidades: os desafios da saúde ambiental. Saude Soc. 1999; 8(1):49-61.

6. Alencar LD, Barbosa MFN. Educação Ambiental no Ensino Superior: ditames da Política Nacional de Educação Ambiental. RDAS. 2018; 8(2):229-55.

7. Marconi MA, Lakatos EM. Fundamentos de metodologia científica. 6.ed. São Paulo, SP: Atlas; 2005.

8. Prodanov CC, Freitas EC. Metodologia do trabalho científico: métodos e técnicas da pesquisa e do trabalho acadêmico. 2.ed. Novo Hamburgo: Feevale; 2013
9. Online Pesquisa. Criar Pesquisa. Zurich, Switzerland, 2019. [acesso em 2019 jun 15] Disponível em: https://www.onlinepesquisa.com/criarpesquisa.

10. Leff E. Educação Ambiental e Desenvolvimento Sustentável. In: Reigota M. (org.) Verde cotidiano, o meio ambiente em discussão. Rio de Janeiro: DP\&A; 1999.

11. Silva ML. A educação ambiental no ensino superior brasileiro: do panorama nacional às concepções de alunos (as) de pedagogia na Amazônia. Revista Eletrônica do Mestrado em Educação Ambiental. 2013; esp. 18-33.

12. Zupelari MFZ, Wick MAL. A incerteza do futuro e a questão ambiental na contemporaneidade. Rev. Subj. 2015; 15(1):9-16.

13. Jesus SJA. O papel da educação em saúde frente às implicações da Atenção Básica: do profissional á comunidade. Revista Interfaces Saúde, Humanas e Tecnologia. 2015; 2(7):1-9.

14. Tramontina LT, Carniatto I. Influências da Educação Ambiental, do grau de escolaridade e do ambiente de trabalho em práticas ambientais por trabalhadores na indústria. Revbea. 2019; 14(1):29-48.

15. Paixão JA Educação ambiental na Educação Básica: elementos para se pensar o trabalho da dimensão ambiental nas aulas de Educação Física. Horizontes. 2018; 36(1):196-207.

16. Brasil. Secretaria de Educação Fundamental. Parâmetros Curriculares Nacionais: Meio Ambiente. Brasília, DF; 1997.

17. Morales AGM. A formação dos profissionais educadores ambientais e a universidade: trajetórias dos cursos de especialização no contexto brasileiro. Educar, Curitiba. 2009. (34):185-99. 